\title{
Design of Self-erecting Tower for a Wind Turbine
}

\author{
Auwal Ibrahim $^{1}$, I. S. Diso ${ }^{2}$, S. T. Auwal ${ }^{1}$, Musa Alhaji Ibrahim ${ }^{1}$, M. S. Dambatta ${ }^{1}$, and S. Ramesh \\ ${ }^{1}$ Department of Mechanical Engineering, Faculty of Engineering, Kano University of Science and \\ Technology, Wudil, 3244 Kano, Nigeria \\ ${ }^{2}$ Department of Mechanical Engineering, Faculty of Engineering, Bayero University 3011 Kano, Nigeria \\ ${ }^{3}$ Center of Advanced Manufacturing and Materials Processing (AMMP), Department of Mechanical \\ Engineering, Faculty of Engineering, University of Malaya, 50603 Kuala Lumpur, Malaysia
}

\begin{abstract}
The rise in total installed wind energy structures globally demonstrated the dominance of wind energy among the means of sustainable energy production. However, the major challenge in the installation of horizontal-axis wind turbines is the use of mobile cranes to install the components. This research reports on a new method of installing the wind turbine without the use of a mobile crane. A self-erecting design was proposed, in which the whole components of tower and turbine will be assembled at the installation site. The highest peak wind speed adopted for the site under research was $56 \mathrm{~km} / \mathrm{h}$, the thickness of base plates material that connected the tower to the base was $11 \mathrm{~mm}$, and the calculated size of jack recommended to lift the tower was 2575 $\mathrm{kg}$. Also, the stiffness of the weak section of the tower was calculated to be $8633 \mathrm{kN} / \mathrm{m}$, and the frequency of vibration of the tower was found to be $191 \mathrm{~Hz}$. A $48 \mathrm{~V}, 1600 \mathrm{~W}$ A.C wind turbine was selected to be installed on the tower under design for the analys is of forces acting on the tower. The wind speed data used for the chosen site was recorded during the raining season in Kano. The design considered a tubular steel tower, from steel pipes that are symmetrical in diameter, but with the diameter of the pipes increasing toward the base: $51 \mathrm{~mm}, 73 \mathrm{~mm}$ and $89 \mathrm{~mm}$. The pipes were to be assembled together using steel reducer sockets, and then to be welded to obtain a permanent solid tower. The erection of the tower was designed to be achieved by the use of a jack, preferably electric jack that requires less effort to operate, attached at the fulcrum, while the tower tilted at the pivot that connected the tower to the base. The proposed structural advancement can meet the design requirements and lower the construction cost of the tower significantly.
\end{abstract}

Key Words: Self-Erecting, Electric Jack, Wind Turbines, Structural Design, Steel Tower.

\section{INTRODUCTION}

In recent years, the need for sustainable energy resulted in a plethora of innovative technological solutions. Thus, the clear energy sources (the wind and the sun) have received considerable attention. Among the latter efforts, the wind plays a predominant role on the scene of clear energy production [1,2]. To further exploit the wind potential, the actions on the towers equally increased and their safe and economical design became essential for increased advancement of the wind energy sector [3]. Nowadays, the cost of the tower constitutes more than $25 \%$ of the initial wind turbine system [4, 5]. Therefore, a considerable number of authors have focused on improving the structural designs of wind turbine towers in recent years to reduce the cost of the tower.

Generally, a tower is a tall structure, taller than its width, often by a significant margin. Towers are distinguished from masts by their lack of guy-wires and are therefore, along with tall buildings and self-supporting structures. Towers can be stand-alone structures or be supported by adjacent buildings or can be a feature on top of a large structure or building. Towers are specifically distinguished from buildings in that they are not built to be habitable but to serve other functions. The principal function of towers is the use of their height to enable various functions to be achieved including visibility of other features attached to the tower such as clock towers, as part of a larger structure or device to increase the visibility of the surroundings as in a fortified building such as a castle, or as a structural feature as an integral part of a bridge, and can also be used to harness the available sources of energy in 
the atmosphere. The trends in wind turbine design are towards larger machines (over $1 \mathrm{MW}$ ) and towards taller supporting towers. Both of these trends task the ability of conventional installation methods which rely on mobile cranes to install the components. But another study examined possible methods of installing the tower and wind turbine without the use of cranes. One of the methods selected by this project was a system involving self-erecting design, in which the whole components can be erected up and down by changing the angle of inclination of the tower, between any angles above zero degree to the horizontal, to the highest angle of 90 degrees to the horizontal. This self-erection of the tower will enable easy access to the components of the turbine during installation and maintenance of the machine.

Improving the structural design of towers has been the focus of many researchers. Wang [6] studied the high resolution tower shadow model for downwind wind turbines, their results showed that there was a strong impulsive response of the blade loading, when the blade was passing out of the tower shadow. In another study, Murtagh [7] investigated the wind response of a wind turbine tower with blade coupling subjected to rotationally sampled turbulence wind loading and found that the resultant base shear stress was imparted at the top of the tower. A study on optimal design of a steel tower shell thickness of 2 MW class wind turbine system through the numerical analysis of natural frequency, strength, fatigue and buckling depending on the shell thickness change is carried out. It confirmed that the final proposed tower meets the tower design requirement [8]. Hong and coworkers reported on the vibration characteristics of steel towers for a large wind power turbine system considering wind loads and seismic loads. The author showed that the guyed steel wire elements reduced the seismic base shear by about $15 \%$ of the design value [9]. A study funded by the windPACT program examined possible methods for installing the tower and wind turbine without the use of cranes. One of the methods selected was a system involving a frame which could climb the tower [10]. Nevertheless, contemporary tower structures are constantly taller, thus, requiring an increase in the thickness and material used for their construction $[11,12]$. These theoretical contributions on towers and wind turbines research, development and findings are still the foundations of today's tower and wind turbine theories. The system introduced by this paper involves a self-erecting design, in which the whole components can be erected up and down by changing the angle of inclination of the tower, between any angles above zero degree to the horizontal, to the highest angle of 90 degrees to the horizontal. This research work will encourage the use of small wind turbines especially for domestic applications, and this is a welcome development in fighting global warming.

\subsection{Research Problem}

Wind turbines are installed on a long tower usually of cylindrical metal, which exposes the turbine to a higher wind current, but which makes accessibility to the turbine difficult, especially during maintenance and repair of the machine. With this research work, of self-erecting towers for the wind turbine, which expressed the idea that the whole turbine machine can be erected up and down without the use of a mobile crane, this difficulty can be overcome especially for small wind turbines that can be used for domestic power generation.

\subsection{Research Methodology}

The methodology employed in this research work involved the following:

i. Collection of wind speed data;

ii. Calculation of the average wind speed of the area and determining the peak wind speed;

iii. Measurement of weight of the wind turbine and its accessories;

iv. Calculation of the tower diameter in steps of length, from the largest diameter at the base of the tower to the smallest diameter at the top of the tower;

v. Selection of the size of jack to lift the tower by analyzing the moment of forces on the jack;

vi. Calculation of the base plates thickness, hinges and size of bolts and nuts to be used;

\section{MATERIALS AND METHODS}

The materials used in this research work include locally available materials such as steel pipes, steel reducer sockets, metal plates, metal rod, bolt and nuts, and metal shaft. Some standard instruments such as a multi-meter (Max: 10A, 600V), weighing balance (capacity range: $0.01 \mathrm{~g}$ to $6 \mathrm{~kg}$ ), two Anemometers ( 0 to $99 \mathrm{mph}$; 0 to $159 \mathrm{~km} / \mathrm{h}$ ) and digital Vernier caliper were used.

The selection of a proper material for engineering purposes is one of the most difficult problems for the designer. The best material is one which serves the designed objective at the minimum cost. The important properties which determine the utility of the material are physical, chemical and mechanical properties. The mechanical properties of the metals are those which are associated with the ability of the material to resist mechanical forces and load. In this research work, it was intended to design a 
tubular tower using steel material. Steels are classified on the basis of mechanical properties as carbon and low alloy steels, where the main criterion in the selection and inspection of steel is the tensile strength or yield stress. A steel pipe was selected for the construction of this tower. The words pipe and tube are usually interchangeable, but in industry and engineering, the terms are uniquely defined. Depending on the applicable standard to which it is manufactured, pipe is generally specified by a nominal diameter with a constant outside diameter and a schedule that defines the thickness. Tube is most often specified by the outside diameter and wall thickness, but may be specified by any two of outside diameter, inside diameter, and wall thickness. Both "pipe" and "tube" imply a level of rigidity and permanence. In general, "pipe" is the most common term used in most of the world, whereas "tube" is more widely used in the United States. Metallic pipes are commonly made from steel or iron, the finish and metal chemistry are peculiar to the use, fit and form. Typically, metallic piping is made of steel or iron, such as unfinished black (lacquer) steel, carbon steel, stainless steel or galvanized steel, brass, and ductile iron. The manufacturing processes used for the preliminary shaping of the engineering components are known as primary shaping processes. Not only for steel pipes, the common operations used in Mechanical Engineering for primary shaping processes are casting, forging, extruding, rolling, drawing, bending, shearing, welding, spinning, powder metal forming, squeezing etc. Tubing, either metal or plastic, is generally extruded. But the most commonly known processes for metallic pipe manufacture are:

i. Centrifugal casting of hot alloyed metal: is one of the most prominent processes, in which ductile iron pipes are generally manufactured in such a fashion.

ii. $\quad$ Welded pipe manufacturing process (Electric Resistance Welding "ERW" and Electric Fusion Welding "EFW"): which are formed by rolling plates and welding the seam. In pipe manufacture, the weld flash can be removed from the outside or inside surfaces using a scarfing blade. The weld zone can also be heat treated to make the seam less visible. Welded pipe often has tighter dimensional tolerances than seamless, and can be cheaper if manufactured in the same quantities. Large-diameter pipe ( 25 centimeters (10 in) or greater) may be ERW, EFW or submerged arc welded (SAW) pipe.

iii. Drawing manufacturing process: is in which a seamless (SMLS) pipe is formed by drawing a solid billet over a piercing rod to create the hollow shell. Hot drawn steel pipes undergo cold drawing as a further processing. This process produces steel pipes with closer dimensional tolerances, wider range of surface finishes and increases yield and tensile strengths of the material.

Hence, this research work selected a seamless drawn steel pipe for the construction of the tower under design, because historically seamless pipe was regarded as withstanding pressure better than other types, and was often more easily available in the market.

\subsection{Design Considerations}

The height of the tower of a horizontal-axis wind turbine does play a role in how much wind energy will be produced. The speed of wind increases with height, and so any increase in the height of a horizontal wind turbine tower will mean an increase in the amount of electricity that is generated by the turbine. The tower was therefore designed such that the component parts can easily be assembled, dismantled and maintained. The extent to which the equipment can withstand the conditions it was subjected to, during operations was also carefully considered. The three categories of towers are tilt-up, fixed-guyed, and freestanding. In general, there are four common types of towers: Reinforced concrete tower, the Tubular steel tower, the Truss tower, and the Built up shell-tube tower. The one designed in this research work is the tubular steel type and freestanding tower. Towers must be specifically engineered for the lateral thrust of wind power and weight of the turbine components, and should be adequately grounded to protect equipment against high wind damage especially during the rainy season. Some criteria that apply to virtually every good design, were also considered in the design of this self-erecting tower, and they are: Elegance of the idea employed; Robustness of the tower; Cost of production; Resources availability; Time constraint; Skill required and Safety in use.

\subsection{Data Collection at Tal'udu area of Kano City in Nigeria}

The beginning of the rain is usually marked by the incidence of high winds and heavy but scattered squalls. The peak of the rainy season occurs through most of northern Nigeria in August and September, when air from the Atlantic covers the entire country. This period is almost considered as the windiest period in Kano and most parts of northern Nigeria, and therefore, this research work uses the wind speed data collected at this period for this kind of structural design. 
International Journal of Engineering Research And Advanced Technology, Vol.6 (12), December-2020

Table 1. Wind Speed data

\begin{tabular}{|c|c|c|c|c|c|c|c|c|c|c|c|c|}
\hline \multicolumn{8}{|c|}{ Data at $18.5 \mathrm{~m}$ height } & \multicolumn{5}{|c|}{ Data at $10 \mathrm{~m}$ height } \\
\hline $\begin{array}{c}\text { Date in } \\
2015\end{array}$ & Time & $\begin{array}{l}\text { Temp } \\
\text { (DB) } \mathrm{C}\end{array}$ & $\begin{array}{l}\text { Due pt } \\
\text { Temp } \mathrm{C}\end{array}$ & $\begin{array}{l}\mathrm{V}_{\max } \\
\mathrm{km} / \mathrm{h}\end{array}$ & $\begin{array}{c}V_{\text {ave }} \\
\mathrm{km} / \mathrm{h}\end{array}$ & $\begin{array}{r}V_{\text {inst }} \\
\mathrm{km} / \mathrm{h}\end{array}$ & $\begin{array}{l}\text { Wind } \\
\text { dir. }\end{array}$ & $\begin{array}{c}\text { Temp } \\
\text { (DB) }{ }^{0} \mathrm{C}\end{array}$ & $\begin{array}{c}\text { Due pt } \\
\text { Temp }{ }^{0} \mathrm{C}\end{array}$ & $\begin{array}{r}\mathrm{V}_{\max } \\
\mathrm{km} / \mathrm{h}\end{array}$ & $\begin{array}{r}\mathrm{V}_{\text {ave }} \\
\mathrm{km} / \mathrm{h}\end{array}$ & $\begin{array}{r}V_{\text {inst }} \\
\mathrm{km} / \mathrm{h}\end{array}$ \\
\hline $17 / 08$ & $5: 10 \mathrm{pm}$ & 33 & 21 & 16 & 9 & 13 & $\mathrm{SE}$ & 32 & - & 8 & 6 & 5 \\
\hline $24 / 08$ & 5:00pm & 26 & 20 & 24 & 15 & 13 & $\mathrm{E}$ & 21 & 18 & - & 7 & 7 \\
\hline $31 / 08$ & $5: 28 \mathrm{pm}$ & 29 & 23 & 13 & 6 & 8 & SW & 20 & 18 & 8 & 8 & 8 \\
\hline $7 / 09$ & $5: 39 \mathrm{pm}$ & 21 & 21 & 56 & 21 & 26 & $\mathrm{~W}$ & 21 & 19 & 8 & 3 & 4 \\
\hline $14 / 9$ & $1: 36 \mathrm{pm}$ & - & - & 19 & 9 & 9 & SW & 31 & 35 & 7 & 6 & 6 \\
\hline $19 / 10$ & $4: 39 \mathrm{pm}$ & - & - & 17 & 8 & 10 & $\mathrm{~W}$ & 38 & - & 10 & 4 & 6 \\
\hline $26 / 10$ & $4: 46 \mathrm{pm}$ & - & - & 19 & 9 & 7 & $\mathrm{E}$ & 36 & - & 15 & 6 & 5 \\
\hline $2 / 11$ & $5: 53 \mathrm{pm}$ & - & - & 15 & 7 & 7 & $\mathrm{~W}$ & 32 & - & 12 & 5 & 5 \\
\hline $9 / 11$ & $4: 43 \mathrm{pm}$ & - & - & 14 & 7 & 11 & SW & 34 & - & 16 & 3 & 7 \\
\hline
\end{tabular}

This research work adopted the highest peak wind speed $\left(\mathrm{V}_{\max }=56 \mathrm{~km} / \mathrm{h}\right)$ obtained at this chosen site, for the design height and tower analysis to avoid possible damages by excessive wind speed loading.

\section{DESIGN ANALYSIS}

The theoretical power in the wind is given as:

$$
P_{\text {theoretical }}=\frac{1}{2} \rho A V^{3}(\text { Watt })
$$

Where; $\rho=$ density of air $\left(1.201 \mathrm{~kg} / \mathrm{m}^{3}\right.$ at normal temperature and pressure $\left.(\mathrm{NTP})\right)$

$$
\begin{aligned}
& \mathrm{V}=\text { mean air velocity }(\mathrm{m} / \mathrm{s}) \\
& \mathrm{A}=\text { swept area of blades }\left(\mathrm{m}^{2}\right)
\end{aligned}
$$

And the maximum extractable power of the wind by a turbine having satisfied with the Bertz limit, and with a generator working on reasonable efficiency of $\eta \%$ is therefore given by:

$$
P_{\text {extractable }}=\frac{1}{2} \rho A V^{3} \times \frac{59.3}{100} \times \eta
$$

Where $\eta=$ Generator efficiency

The axial force on a turbine wheel $\left(\mathrm{f}_{\mathrm{p}}\right)$ is given as:

$$
f_{p}=\frac{4}{9} \rho A V_{f}^{2}
$$

Where: $\rho=$ density of air $\left(1.201 \mathrm{~kg} / \mathrm{m}^{3}\right.$ at NTP $)$

$\mathrm{V}_{\mathrm{f}}=$ for tower is the highest peak air velocity $(\mathrm{m} / \mathrm{s})$

$A=$ swept area of blades $\left(\mathrm{m}^{2}\right)$

Bending moment on tower $\left(\mathrm{M}_{\mathrm{b}}\right)$ is given by:

$$
\begin{array}{ll} 
& \mathrm{M}_{\mathrm{b}}=\text { force } \mathrm{x} \text { distance } \\
\text { i.e } \quad \mathrm{M}_{\mathrm{b}}=\text { axial force of wind on rotor } \mathrm{x} \text { distance from ground level to turbine height: } \\
\therefore \quad \mathrm{M}_{\mathrm{b}}=f_{p} \times d \ldots \ldots \ldots \ldots \ldots \ldots \ldots(I V)
\end{array}
$$

For this work, a steel pipe is used, and therefore it must be admitted that the cause of failure depends not only on the properties of the materials, but also on the stress system to which it is subjected. According to the Maximum Shear Stress Theory, also known as the Tresca yield criterion, this assumes that "yield occurs when the shear stress exceeds the shear yield strength".

$$
\tau=\frac{\sigma_{1}-\sigma_{3}}{2} \leq \tau_{y}
$$

Let us apply the general maximum shear stress equation, to analyse the tubular tower subjected to axial load and bending moment; 
Weight of turbine machine $\left(\mathrm{p}_{\mathrm{a}}\right)$

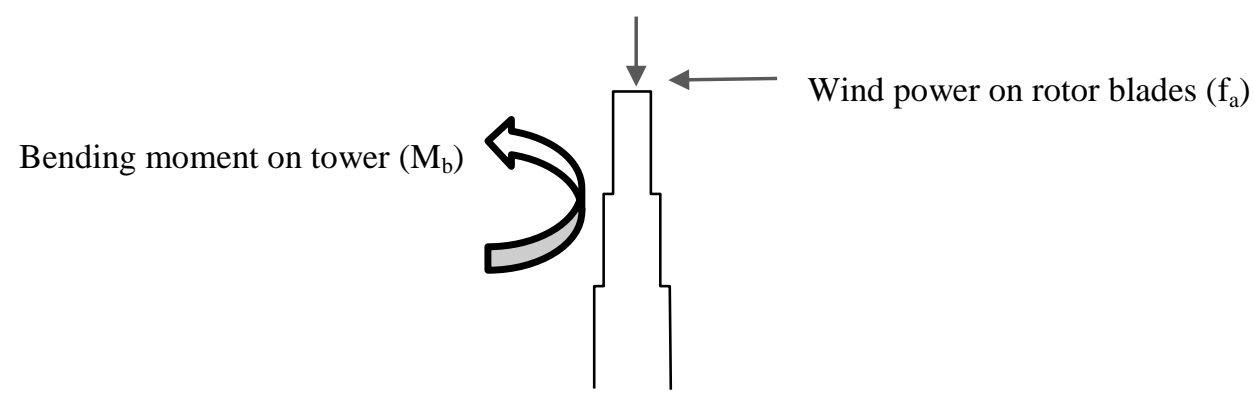

Figure 1. Forces acting on a tower.

The maximum shear stress may be determined using the relation given as:

$$
\tau_{\max }=\frac{16}{\pi d^{3}} \sqrt{\left(K_{m} M_{b}+\alpha \frac{P_{a}}{8}\right)^{2}+\left(K_{t} T\right)^{2}}
$$

Where; $\quad \tau_{\max } \leq \tau_{p} \leq \frac{\tau_{y}}{F S}$

FS $=$ Factor of safety

$K_{m}=1.0$, for gradually applied load

$K_{t}=1.0$, for gradually applied load

$\alpha=1.0$, if there is no column action

$\mathrm{T}=0$, since the torsional load is absent on the tower

Above are recommended values according to IS 4694-1968.

By simplifying the equation and making $\mathrm{d}^{3}$ the subject of the equation, we have;

$$
d^{3}=\frac{16 \sqrt{\left(M_{b}+\frac{P_{a}}{8}\right)^{2}}}{\pi \tau_{p}} \ldots \ldots \ldots \ldots \ldots \ldots \ldots(V I I)
$$

Where; $\mathrm{d}=$ Tower diameter

$\mathrm{M}_{\mathrm{b}}=$ Bending moment on tower

$\mathrm{P}_{\mathrm{a}}=$ weight of turbine machine on tower

$\tau_{\mathrm{p}}=56 \mathrm{MPa}$ (according to ASME code permissible shear stress for shaft without keyway)

For hollow shaft (steel pipe in this case)

$$
d^{3}=d_{o}^{3}\left(1-k^{4}\right)
$$

where; $\mathrm{k}=\frac{d_{i}}{d_{o}}$

$\mathrm{d}_{\mathrm{i}}=$ inside diameter

$\mathrm{d}_{\mathrm{o}}=$ outside diameter

Therefore:

$$
d_{o}=\sqrt[3]{\frac{d^{3}}{1-k^{4}}}=\sqrt[3]{\frac{16 \sqrt{\left(M_{b}+\frac{P_{a}}{8}\right)^{2}}}{\pi \tau_{p}}}
$$


$\mathrm{d}_{\mathrm{o}}=$ outside diameter of the tower

The carbon steel pipe tube fabrication company ranges in sizes from $\frac{1}{8}$ inch to 48 inches. These steel pipes were manufactured in the following sample of wall thickness [13];

Table 2. Standard pipe wall thickness.

\begin{tabular}{|l|l|l|l|l|l|l|}
\hline Pipe size (inch) & 2 & $2 \frac{1}{2} 2$ & 3 & $3 \frac{1}{2}$ & 4 & 5 \\
\hline Wall thickness (mm) & 2.8 & 3 & 3 & 3 & 3 & 4.8 \\
\hline
\end{tabular}

From the table 2, taking the median pipe size of $3 \frac{1}{4}$ inch inside diameter, having $3 \mathrm{~mm}$ wall thickness, after all units' conversion, the factor $\mathrm{k}$ is obtained to be:

$\mathrm{K}=\frac{d_{i}}{d_{o}}=\frac{3}{3.120}=0.96$ (an average ratio from the standard pipes)

For a tower of $18.5 \mathrm{~m}$ height, and considering the tower as having three divisions in length, i.e $6 \mathrm{~m}$ for each of the three divisions (to conform with the length of the standard pipes), while leaving $0.5 \mathrm{~m}$ for the base, this is because of the limitation on accessibility to the steel manufacturing company that can cast the tower in its conical shape, and which also will invite a high cost. But using the available materials in Kano, the tower construction is shown in Figure 2:

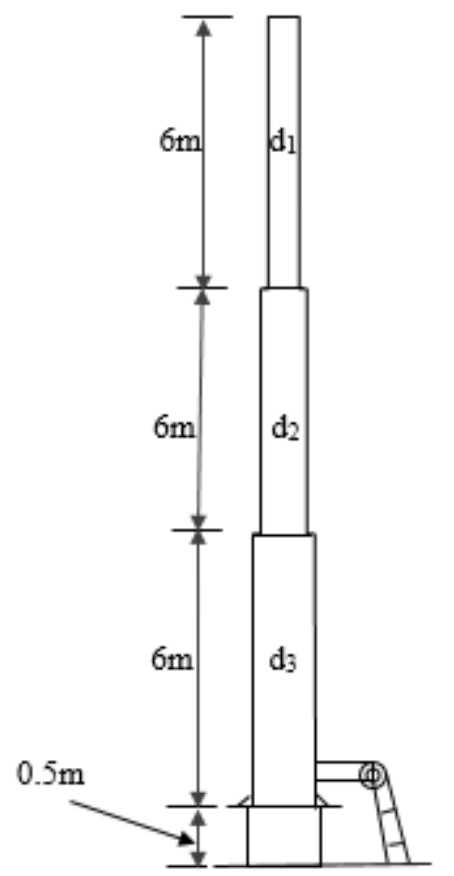

Figure 2. Tower diagram.

For steel pipe tower diameter(d)

The highest peak wind speed of the site at the design height $=56 \mathrm{~km} / \mathrm{h}$

$$
=15.556 \mathrm{~m} / \mathrm{s}
$$

The swept area of the rotor blades $\mathrm{A}=\pi \mathrm{r}^{2}$

Where $\mathrm{r}$ is the radius of the rotor and measured to be $76 \mathrm{~cm}$

$$
\begin{aligned}
A & =\pi \times 0.76^{2} \\
& =1.815 \mathrm{~m}^{2}
\end{aligned}
$$

Axial force of wind power on rotor blades $f_{p}=\frac{4}{9} \rho A V_{f}^{2}$

$$
\begin{aligned}
& =\frac{4}{9} \times 1.201 \times 1.815 \times 15.556^{2} \\
& =234.441 \mathrm{~N}
\end{aligned}
$$


While for force due to weight normal to the tower, the total weight of the turbine machine was multiplied by the gravity, thus $\mathrm{P}_{\mathrm{a}}=$ mass $\times$ gravity

Total weight of turbine machine on tower $=10.581 \mathrm{~kg}$

$$
\text { Therefore, } \mathrm{P}_{\mathrm{a}}=10.581 \times 9.81=103.8 \mathrm{~N}
$$

However, a machine component subjected to an axial compressive force is called a strut. A strut may be horizontal, inclined or even vertical, a vertical strut is known as a column, pillar or stanchion. The first rational attempt to study the stability of long columns was made by Mr. Euler. He derived an equation for the buckling load of long columns based on the bending stress, while deriving this equation, the effect of direct stress was neglected. This may be justified with the statement that "the direct stress induced in a long column is negligible as compared to the bending stress". Consider now the tower as a column material having the end condition of "one end fixed and the other end free", with the forces acting on it as shown in Figure 3:

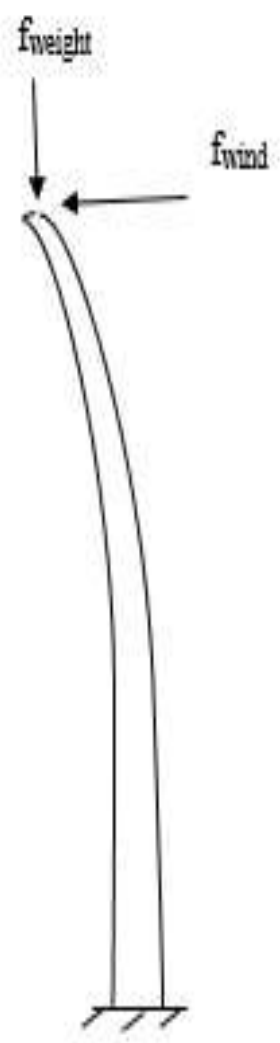

Figure 3. Forces acting on the tower with one end fixed and the other end free.

According to Euler's Theory, the crippling or buckling load under various end conditions is represented by a general equation [14]:

$$
F=\frac{C \pi^{2} E I}{L^{2}}
$$

Where $\quad \mathrm{C}=$ Constant, representing end condition of the column or end fixicity coefficient $(\mathrm{C}=0.25$ for one end fixed and other end free)

$\mathrm{E}=$ Modulus of Elasticity for the material of the column, for Carbon Steel, E = $200 \mathrm{GPa}$ [15]

$\mathrm{I}=$ Area Moment of Inertia (in this case for hollow cylindrical cross section)

$\mathrm{L}=$ Length of the column (Length of the tower for this case)

The crippling or buckling load in this case is the axial force of the wind power on the rotor and the weight of the turbine machine on the tower.

$$
\begin{aligned}
& F=\text { summation of forces on Tower }=f_{\text {wind }} \text { and } f_{\text {weight }} \\
& \qquad f_{\text {wind }}=f_{p} \times F S
\end{aligned}
$$


where FS = Factor of Safety, adopting a factor of safety of 3 as for some machine design [15], which means the peak wind speed measured at the site must triple at least for the tower to tend to buckle.

The Axial force on a turbine wheel $\left(\mathrm{f}_{\mathrm{p}}\right)$ is given by; $f_{p}=\frac{4}{9} \rho A V_{f}^{2}$

Where: $\rho=$ density of air $\left(1.201 \mathrm{~kg} / \mathrm{m}^{3}\right.$ at NTP)

$$
\mathrm{V}_{\mathrm{f}}=\text { for tower is the highest peak air velocity }(\mathrm{m} / \mathrm{s})
$$

The highest peak wind speed of the site at the design height $=56 \mathrm{~km} / \mathrm{h}$

$$
=15.556 \mathrm{~m} / \mathrm{s}
$$

$\mathrm{A}=$ swept area of blades $\left(\mathrm{m}^{2}\right)$

The swept area of the rotor blades $\mathrm{A}=\pi \mathrm{r}^{2}$

Where $r$ is the radius of the rotor and measured to be $76 \mathrm{~cm}$

$$
\therefore \quad \mathrm{A}=\pi \times 0.76^{2}=1.815 \mathrm{~m}^{2}
$$

The axial force $f_{p}=\frac{4}{9} \times 1.201 \times 1.815 \times 15.556^{2}=234.441 \mathrm{~N}$

$$
\therefore \mathrm{f}_{\text {wind }}=234.441 \times 3=703.323 \mathrm{~N}
$$

And $\mathrm{f}_{\text {weight }}=$ Weight of Turbine machine

$$
=\text { mass in }(\mathrm{kg}) \times \text { gravity in }\left(\mathrm{m} / \mathrm{s}^{2}\right)
$$

$$
\therefore \quad \mathrm{f}_{\text {weight }}=10.581 \times 9.81=103.8 \mathrm{~N}
$$

Since $\mathrm{f}_{\text {weight }}$ and $\mathrm{f}_{\text {wind }}$ act in different directions, they cannot be added by ordinary algebraic methods.

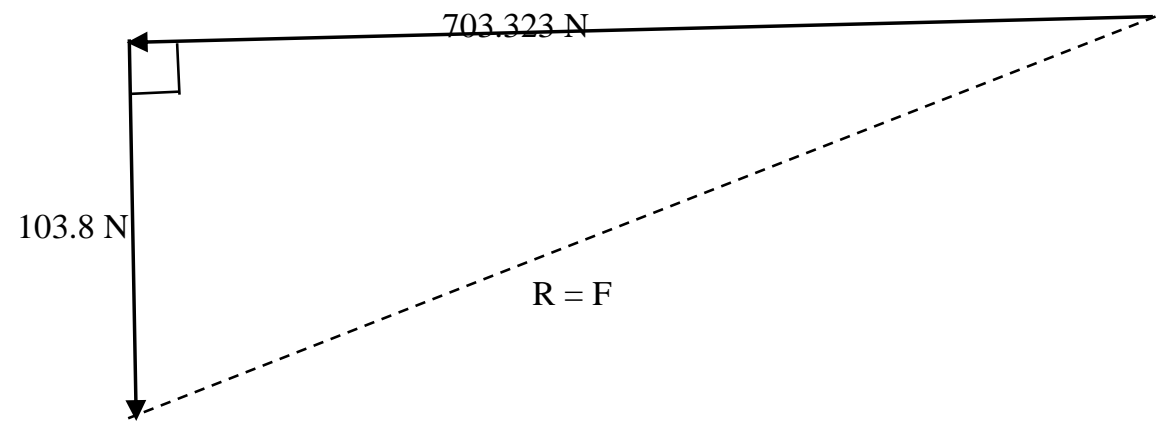

By Pythagoras Theorem: $\mathrm{R}^{2}=103.8^{2}+703.323^{2}$

$$
\begin{aligned}
\therefore \quad \mathrm{R} & =\sqrt{505437.682}=\mathrm{F} \\
\mathrm{F} & =710.941 \mathrm{~N}
\end{aligned}
$$

$$
\begin{array}{r}
\therefore F=\frac{C \pi^{2} E I}{L^{2}}=710.941 \\
I=I y=\frac{\pi\left(d_{o}^{4}-d_{i}^{4}\right)}{64}=\frac{\pi}{64} d_{o}^{4}\left(1-K^{4}\right) .
\end{array}
$$

Where $K=\frac{d_{i}}{d_{o}}$

$\mathrm{d}_{\mathrm{i}}=$ internal diameter of the tower pipe material

$\mathrm{d}_{\mathrm{o}}=$ outside diameter of the tower pipe material

But $\mathrm{K}$ is already calculated to be 0.96

$$
\frac{C \pi^{3} E d_{o}^{4}\left(1-K^{4}\right)}{64 L^{2}}=710.941
$$




$$
\begin{gathered}
d_{o}^{4}=\frac{45500.25 L^{2}}{C \pi^{3} E\left(1-K^{4}\right)} \\
d_{o}=\sqrt[4]{\frac{64 F L^{2}}{C \pi^{3} E\left(1-K^{4}\right)}} \ldots \ldots \ldots \ldots \ldots \ldots \ldots \ldots(X I I)
\end{gathered}
$$

For the top 1st part of the tower $\left(\mathrm{d}_{1}\right)$

$$
d_{o_{1}}=\sqrt[4]{\frac{45500.25 \times 6^{2}}{0.25 \times \pi^{3} \times 200 \times 10^{9}\left(1-0.96^{4}\right)}}
$$

$$
\begin{aligned}
& =0.051 \mathrm{~m} \\
& =51 \mathrm{~mm} \\
& =2.008 \mathrm{in} \\
& =2-i n c h \text { pipe }
\end{aligned}
$$

For the 2nd part of the tower $\left(\mathrm{d}_{2}\right)$

$$
d_{o_{2}}=\sqrt[4]{\frac{45500.25 \times 12^{2}}{0.25 \times \pi^{3} \times 200 \times 10^{9}\left(1-0.96^{4}\right)}}
$$

$$
\begin{aligned}
& =0.073 \mathrm{~m} \\
& =73 \mathrm{~mm} \\
& =2.874 \mathrm{in} \\
& =3 \text {-inch pipe }
\end{aligned}
$$

For the 3rd part (base) of the tower $\left(\mathrm{d}_{3}\right)$

$$
d_{o_{3}}=\sqrt[4]{\frac{45500.25 \times 18^{2}}{0.25 \times \pi^{3} \times 200 \times 10^{9}\left(1-0.96^{4}\right)}}
$$

$$
\begin{aligned}
& =0.089 \mathrm{~m} \\
& =89 \mathrm{~mm} \\
& =3.504 \mathrm{in} \\
& =4-i n c h \text { pipe }
\end{aligned}
$$

Hence; it is recommended to consider the tower as a long column, which is satisfied by the analysis of the tower using Euler's theory. But failure occurs mainly at the weak point of Engineering materials, the part of the tower with the smallest diameter is within the 2-inch pipe. The outside and inside diameters of the pipe was measured for Danny steel (B.S1387-1983) pipe: $\mathrm{d}_{0}=56.5$ $\mathrm{mm}, \mathrm{di}=52.5 \mathrm{~mm}$

The stiffness of the tower in this section is given by:

$$
\mathrm{K}=\frac{A E}{L}
$$

Where: $\mathrm{L}=$ length of the pipe $=6 \mathrm{~m}$,

E $=$ Modulus of Elasticity, for Carbon Steel, E = $200 \mathrm{GPa}$, [16]

$\mathrm{A}=$ Cross-sectional area of the pipe $=\frac{\pi}{4} \times\left(0.0565^{2}-0.0535^{2}\right)=0.000259 \mathrm{~m}^{2}$

$$
\therefore \text { Stiffness }(K)=\frac{0.000259 \times 200 \times 10^{9}}{6}=8633 \mathrm{kN} / \mathrm{m}
$$

By knowing the stiffness of the tower, the natural frequency of the tower can also be calculated as follows: 


$$
f_{n}=\frac{1}{2 \pi} \sqrt{\frac{K}{m}} \ldots \ldots \ldots \ldots \ldots
$$

Where: $\mathrm{K}=$ Stiffness of the tower $=8633 \mathrm{kN} / \mathrm{m}$

$\mathrm{m}=$ mass of the tower $=79.413 \mathrm{~kg}$ (refer to Fig. 4$)$

$$
\therefore \text { Natural frequency }\left(f_{n}\right)=\frac{1}{2 \pi} \sqrt{\frac{8633333}{6}}=191 \mathrm{~Hz}
$$

Note that, when the forcing frequency on a mechanical system matches the system's natural frequency of vibration, then the system is said to be at resonant frequency. This causes violent swaying motions and even catastrophic failure, which termed as resonance disaster. Avoiding resonance disasters is a major concern in every building, tower and bridge construction.

\subsection{Selection of a Jack}

A jack is a mechanical device used as a lifting device to lift heavy loads or to apply great force. Most mechanical jacks employ a screw thread for lifting heavy equipment, however a hydraulic jack uses hydraulic power to raise loads. Some of the common jacks in use are; Scissor car jacks, which usually use mechanical advantage to allow a human to lift a vehicle by manual force alone. Hydraulic jacks use a fluid which is incompressible, that is forced into a cylinder by a pump plunger. A pneumatic jack is a hydraulic jack that is actuated by a compressed air. A strand jack is a specialized hydraulic jack that grips steel cables often used in concert, strand jacks can lift hundreds of tons and are used in Engineering and construction. A house jack also called a screw jack, is a mechanical device primarily used to lift buildings from their foundations for repairs or relocation. The farm jack is also known as a Hi-Lift Jack, it consists of a steel beam with a series of equally spaced holes along its length, and a hand operated mechanism which can be moved from one end of the beam to the other through the use of a pair of climbing pins.

But electrically operated jacks are mostly operated by electric motors, the electrical energy is used to power these jacks to raise and lower the load automatically. Electric jacks require less effort to operate. National and international standards have been developed to standardize the safety and performance requirements for jacks and other lifting devices.

Jacks are usually rated for a maximum lifting capacity, that's why to select a jack, one has to determine the amount of weight to be lifted by the jack.

$\therefore$ Components of weight to be lifted by the jack $=$ weight of tower + weight of turbine machine

But weight of tower $=$ weight of 2 " pipe + weight of 3 " pipe + weight of 4 " pipe

Inspection of steel pipe at Kofar-ruwa market in Kano city reveals the availability and quality standard of G-Type steel pipe with the following approximate dimensions of the required sizes of pipes;

$$
\begin{aligned}
& \text { 2-inch pipe has } \left.d_{o}=56.5 \mathrm{~mm}, d_{i}=53.5 \mathrm{~mm} \text { (Danny Steel B. } \mathrm{S} 1387-1983\right) \\
& \text { 3-inch pipe has } \left.d_{o}=85.1 \mathrm{~mm}, d_{i}=81.1 \mathrm{~mm} \text { (Danny Steel B. } \mathrm{S} 1387-1985\right) \\
& \text { 4-inch pipe has } d_{o}=110.6 \mathrm{~mm}, d_{i}=105.6 \mathrm{~mm} \text { (Danny Steel B. S 1387-1987) }
\end{aligned}
$$

While the standard length of steel pipe is obtained to be 6 meters

Also, the density of carbon steel varies based on the alloying constituents. It usually ranges between $7750 \mathrm{~kg} / \mathrm{m}^{3} \mathrm{and} 8050 \mathrm{~kg} / \mathrm{m}^{3}$. But the approximate value usually taken as density of steel is $7850 \mathrm{~kg} / \mathrm{m}^{3}$.

However, weight measurement of pipes and reducers using a weighing scale gives the following values:

Weight of 2" pipe with 3"- 2" reducer socket $=13.154 \mathrm{~kg}$

Weight of 3" pipe $=21.886 \mathrm{~kg}$

Weight of 4" pipe with 6"- 4" and 4"- 3" reducer sockets $=33.792 \mathrm{~kg}$

Total weight of tower pipes and joining sockets materials $=68.832 \mathrm{~kg}$

Weight of turbine machine $\left(\mathrm{W}_{\text {Turbine }}\right)=10.581 \mathrm{~kg}$

$\therefore \quad$ Total weight of the assembly $=\mathrm{W}_{\text {pipes }}+\mathrm{W}_{\text {Turbine }}=79.413 \mathrm{~kg}$ 
To determine the forces acting on the tower during the self-erection; let consider that the jack is lifting the load from the fulcrum not from the centre of gravity of the Tower, this made the load to be a moment of forces on the jack.

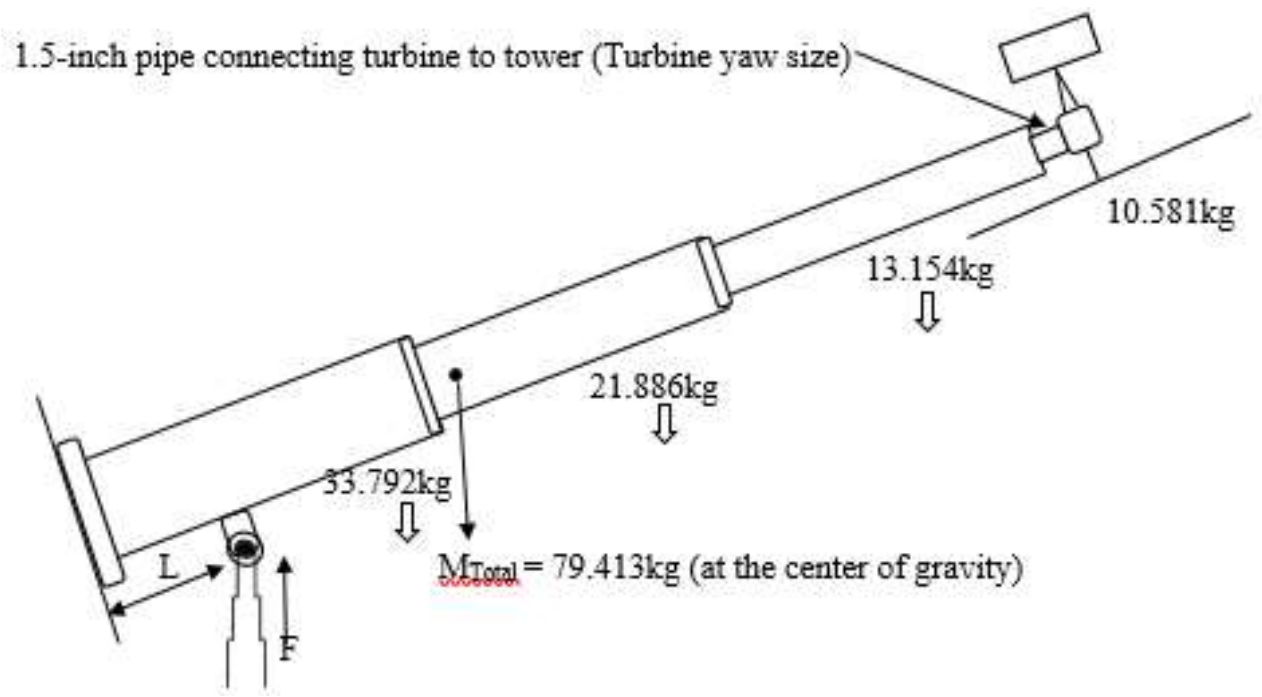

Figure 4. Free Body Diagram.

Work done by the jack in lifting the tower $=$ Moment of forces acting on the jack

We consider the center of gravity of each pipe to be at mid-length of the pipe

$\therefore \mathrm{W}_{\text {jack }}=$ Moment $_{\text {jack }}=\sum \quad\left\{3 F_{p_{3}}, 9 F_{p_{2}}, 15 F_{p_{1}}, 18 F_{\text {Turbine }}\right\}$

$=((3 \times 33.792 \times 9.81)+(9 \times 21.886 \times 9.81)+(15 \times 13.154 \times 9.81)+(18 \times 10.581 \times 9.81))=6730.818 \mathrm{Nm}$

A counter moment is required, to serve as a resisting moment to the above overturning moments on jack.

$$
\text { But; Factor of safety }=\frac{\text { Resisting Moment }}{\text { Overturning Moment }} \quad \text { i.e F.S }=\frac{\sum \quad M_{R}}{\sum \quad M_{O}} \ldots \ldots(X V)
$$

$\therefore$ Resisting Moments $\left(\sum \quad M_{R}\right)=$ F.s $\times \sum \quad M_{O}=3 \times 6730.818=20192.454 \mathrm{Nm}$

The size of the jack to overcome this moment depends on the position, distance from the pivot to which the jack lifts the tower.

Now if we are to select to lift the tower from a position $1 \mathrm{~m}$ from the pivot

$\therefore \quad$ Force required to lift the Tower $=\frac{20192.454 \mathrm{Nm}}{1 \mathrm{~m}}=20192.454 \mathrm{~N}$

$$
\begin{aligned}
& =2058.4 \mathrm{~kg} \\
& =4537.9 \mathrm{lb} .
\end{aligned}
$$

If we are to use the jack to a maximum of $80 \%$ of its recommended capacity as a means of factor of safety.

i.e. Jack size $=\frac{\text { Load }}{4} \times 5=80 \%$ maximum utilization

Then we are selecting a jack of size $=\frac{20192.454}{4} \times 5 \cong 25,250 \mathrm{~N}$ at $1 \mathrm{~m}$ from the pivot

$\cong 12,630 \mathrm{~N}$ at $2 \mathrm{~m}$ from the pivot

$=\frac{2058.4}{4} \times 5 \cong 2,575 \mathrm{~kg}$ at $1 \mathrm{~m}$ from the pivot

$\cong 1,290 \mathrm{~kg}$ at $2 \mathrm{~m}$ from the pivot

$=\frac{4537.9}{4} \times 5 \cong 5,675 \mathrm{lb}$. at $1 \mathrm{~m}$ from the pivot

$\cong 2,840 \mathrm{lb}$. at $2 \mathrm{~m}$ from the pivot 
The selected jack may be larger or smaller than the above calculated sizes depending on the adjustment made in locating the fulcrum, which will also be determined by the maximum extended length of the selected jack compared to those available in the markets. However, due to the market survey for available jacks at Kano markets, this paper adopted locating the fulcrum at $1 \mathrm{~m}$ for the for the subsequent analyses of this tower.

Having a Weight of 4" pipe with 6"- 4" and 4"- 3" reducer sockets $=33.792 \mathrm{~kg}$, and span across a length of $6 \mathrm{~m}$

Then force acting on tower from bottom of the tower to the fulcrum $=\frac{33.792 \mathrm{~kg}}{6}=5.632 \mathrm{~kg}=55.250 \mathrm{~N}$ i.e $5.632 \mathrm{~kg}=55.250 \mathrm{~N}$ at $0.5 \mathrm{~m}$ (at a center of gravity of the span)

Other forces acting downward are: $28.160 \mathrm{~kg}=276.250 \mathrm{~N}$ at $3.5 \mathrm{~m}$

$$
\begin{aligned}
& 21.886 \mathrm{~kg}=214.702 \mathrm{~N} \text { at } 9 \mathrm{~m} \\
& 13.154 \mathrm{~kg}=129.041 \mathrm{~N} \text { at } 15 \mathrm{~m} \\
& 10.581 \mathrm{~kg}=103.800 \mathrm{~N} \text { at } 18 \mathrm{~m}
\end{aligned}
$$

Also the force acting upward by the action of jack is calculated to be $20192.454 \mathrm{~N}$

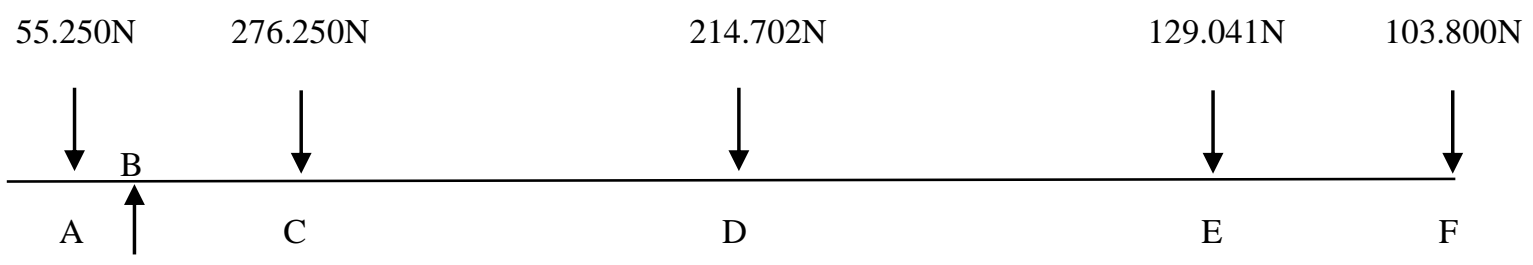

$20192.454 \mathrm{~N}$

Type equation here. if $0<\mathrm{x}<0.5 \mathrm{~m} \quad \mathrm{SF}_{\mathrm{A}}=-55.250 \mathrm{~N}$

$$
\begin{aligned}
& 0.5 \mathrm{~m}<\mathrm{x}<1 \mathrm{~m} \quad \mathrm{SF}_{\mathrm{B}}=-55.250+20192.454=20137.204 \mathrm{~N} \\
& 1 \mathrm{~m}<\mathrm{x}<3.5 \mathrm{~m} \quad \mathrm{SF}_{\mathrm{C}}=20137.204-276.250=19860.954 \mathrm{~N} \\
& 3.5 \mathrm{~m}<\mathrm{x}<9 \mathrm{~m} \quad \mathrm{SF}_{\mathrm{D}}=19860.954-214.702=19646.252 \mathrm{~N} \\
& 9 \mathrm{~m}<\mathrm{x}<15 \mathrm{~m} \quad \mathrm{SF}_{\mathrm{E}}=19646.252-129.041=19517.211 \mathrm{~N} \\
& \mathrm{x}=18 \mathrm{~m} \quad \mathrm{SF}_{\mathrm{F}}=19517.211-103.800=19413.411 \mathrm{~N} \text { (Lifting force) }
\end{aligned}
$$

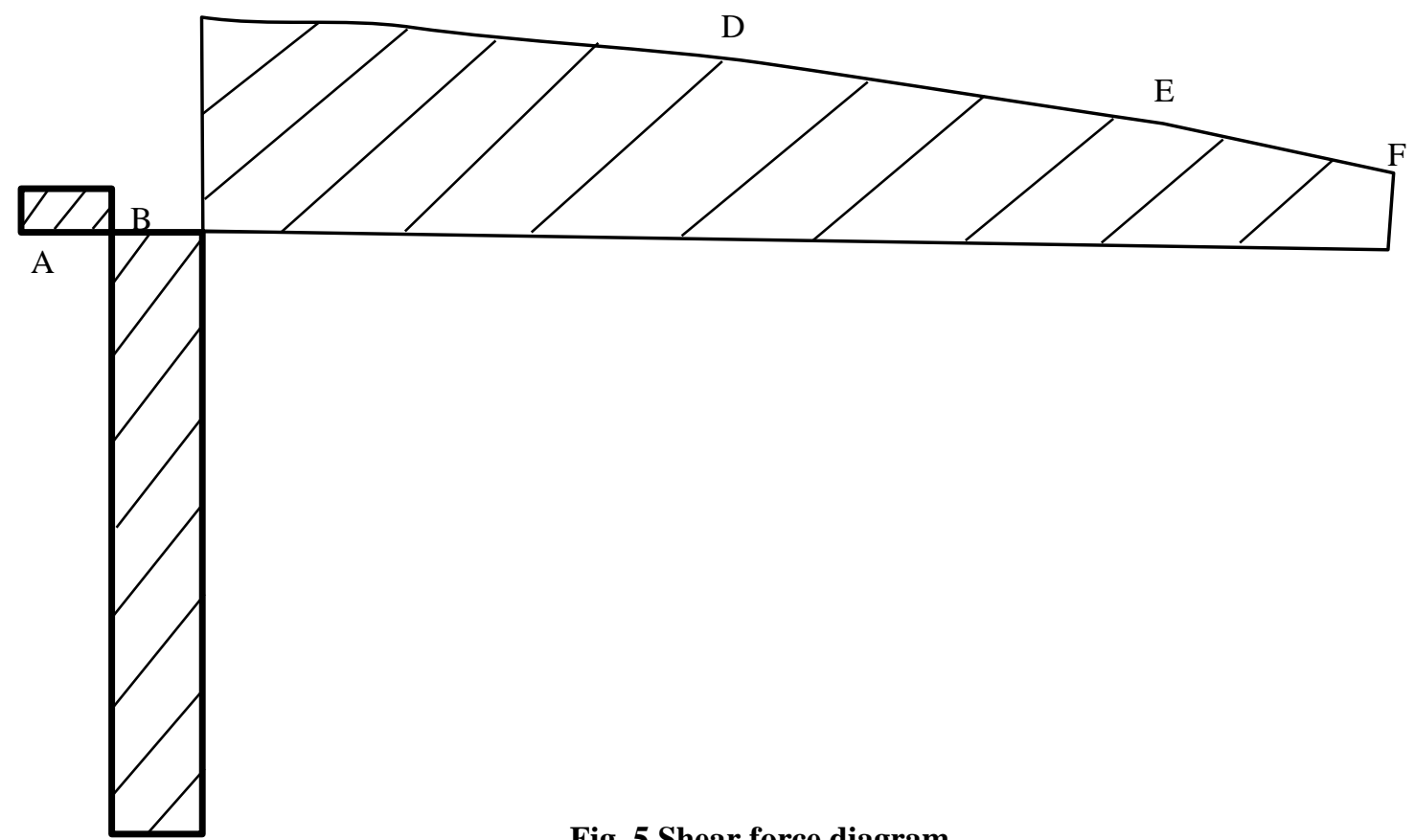

Fig. 5 Shear force diagram 
Then the bending moment on tower during the erection, is the algebraic sum of all the moment of forces and concentrated moments to one side of the side of the tower;

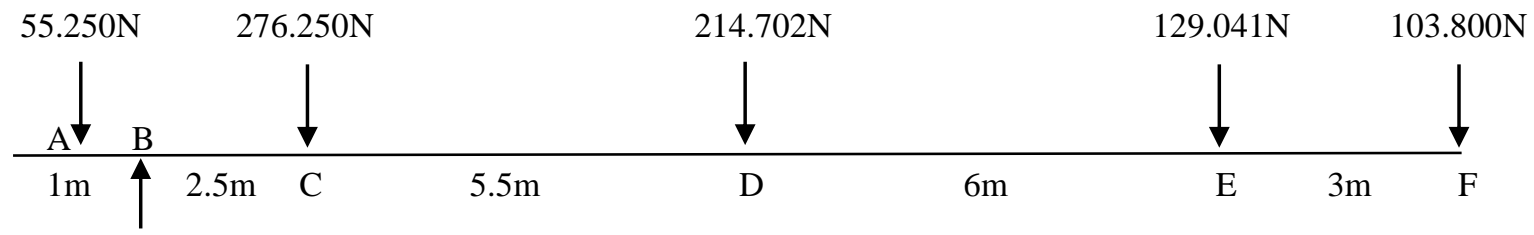

$20192.454 \mathrm{~N}$

Now taking moment about point $\mathrm{F}$

$$
\begin{aligned}
& 0<x<0.5 m \\
& \text { If } x=0 \\
& \text { If } x=0.5 \mathrm{~m} \\
& 0.5 \mathrm{~m}<\mathrm{x}<1 \mathrm{~m} \\
& \text { If } \mathrm{x}=0.5 \mathrm{~m} \\
& \text { If } x=1 \mathrm{~m} \\
& 1 \mathrm{~m}<\mathrm{x}<3.5 \mathrm{~m} \\
& \text { If } x=1 \\
& \text { If } x=3.5 \\
& 3.5 \mathrm{~m}<\mathrm{x}<9 \mathrm{~m} \\
& \text { If } x=3.5 \mathrm{~m} \\
& \text { If } x=9 \mathrm{~m} \\
& \mathrm{BM}_{\mathrm{A}}=-55.250 \mathrm{x} \\
& \mathrm{BM}_{\mathrm{A}}=0 \\
& \mathrm{BM}_{\mathrm{A}}=27.625 \mathrm{Nm} \\
& \mathrm{BM}_{\mathrm{B}}=-55.250 \mathrm{x}+20192.454(\mathrm{x}-0.5) \\
& \mathrm{BM}_{\mathrm{B}}=27.625 \mathrm{Nm} \\
& \mathrm{BM}_{\mathrm{B}}=10040.977 \mathrm{Nm} \\
& \mathrm{BM}_{\mathrm{C}}=-55.250 \mathrm{x}+(20192.454(\mathrm{x}-0.5))-(267.250(\mathrm{x}-1)) \\
& \mathrm{BM}_{\mathrm{C}}=10040.977 \mathrm{Nm} \\
& \mathrm{BM}_{\mathrm{C}}=59715.862 \mathrm{Nm} \\
& \mathrm{BM}_{\mathrm{D}}=-55.250 \mathrm{x}+(20192.454(\mathrm{x}-0.5))-(267.250(\mathrm{x}-1))-(214.702(\mathrm{x}-3.5)) \\
& \mathrm{BM}_{\mathrm{D}}=59715.862 \mathrm{Nm} \\
& \mathrm{BM}_{\mathrm{D}}=167819.748 \mathrm{Nm} \\
& \mathrm{BM}_{\mathrm{E}}=-55.250 \mathrm{x}+(20192.454(\mathrm{x}-0.5))-(267.250(\mathrm{x}-1))-(214.702(\mathrm{x}-3.5))- \\
& (129.041(\mathrm{x}-9)) \\
& \text { If } \mathrm{x}=9 \mathrm{~m} \quad \mathrm{BM}_{\mathrm{E}}=167819.748 \mathrm{Nm} \\
& \text { If } \mathrm{x}=15 \mathrm{~m} \quad \mathrm{BM}_{\mathrm{E}}=284977.014 \mathrm{Nm} \\
& 15 \mathrm{~m}<\mathrm{x}<18 \mathrm{~m} \\
& \text { If } x=15 m \\
& \mathrm{BM}_{\mathrm{F}}=-55.250 \mathrm{x}+(20192.454(\mathrm{x}-0.5))-(267.250(\mathrm{x}-1))-(214.702(\mathrm{x}-3.5))- \\
& (129.041(\mathrm{x}-9))-(103.800(\mathrm{x}-15)) \\
& \text { If } x=18 \mathrm{~m} \\
& \mathrm{BM}_{\mathrm{F}}=284977.014 \mathrm{Nm} \\
& \mathrm{BM}_{\mathrm{F}}=343631.370 \mathrm{Nm}
\end{aligned}
$$




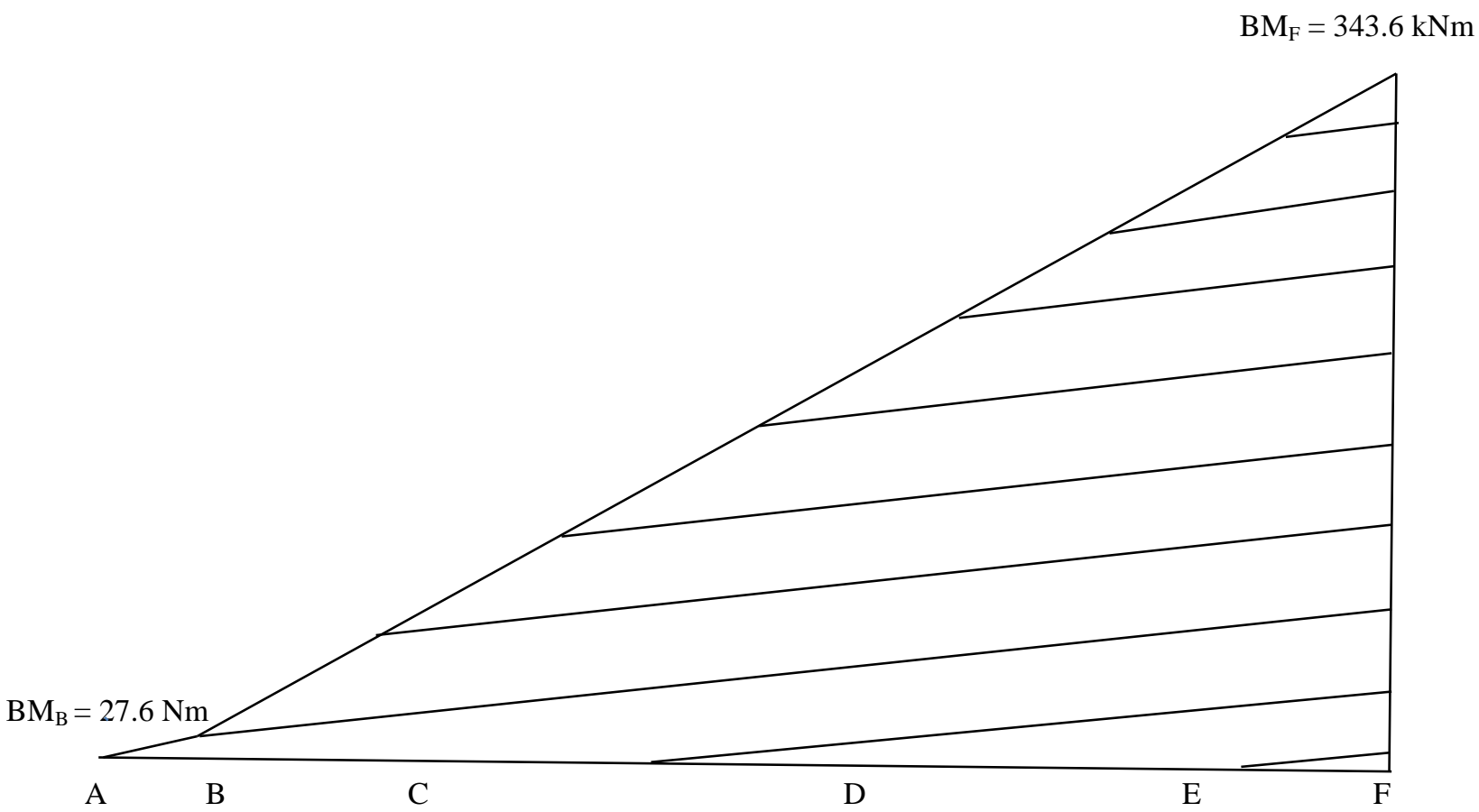

Fig. 6 Bending moment diagram

\subsection{Design of base plates, bolts and hinges}

Let us consider the base plate to be subjected to bending stress by the action wind power on tower, therefore by knowing the tensile stress of the base plate material, the thickness of the base plate may be determined by using the bending equation [14]:

$$
\sigma_{t}=\frac{M}{Z}
$$

Where: $\mathrm{M}=$ Bending moment on base plate

$\sigma_{\mathrm{t}}=$ Tensile stress of base plate material $\left(\sigma_{\mathrm{t}}=\right.$ allowable stress for steel $\left.=52 \mathrm{MPa}\right)$

$\mathrm{Z}=\frac{1}{6} w t^{2}$

Where: $\quad w=$ width of the plate $(w=300 \mathrm{~mm}$ as in Figure 5)

$\mathrm{t}=$ thickness of the base plate

But the forces acting on the base plate are $\left(f_{\text {weight of tower \& turbine }}\right)$ and $\left(f_{\text {wind }}\right)$

Since $f_{\text {weight }}$ and $f_{\text {wind }}$ act in different directions, they can only be added by geometric method.

$\therefore \mathrm{F}=\mathrm{R}$

$$
\begin{aligned}
\text { By Pythagoras Theorem: } \quad R^{2}=779^{2}+703.323^{2} \\
R=\sqrt{1101504.242}=F
\end{aligned}
$$

$\therefore \mathrm{F}=1049.526 \mathrm{~N}$

Therefore, from equation $X V I$

$$
\begin{gathered}
Z=\frac{M}{\sigma_{t}}=\frac{F \times w}{\sigma_{t}}=\frac{1049.526 \times 0.3}{52 \times 10^{6}}=0.00000605 \mathrm{~m}^{3}=\frac{1}{6} w t^{2} \\
\therefore \quad t=\sqrt{\frac{6 \times 0.00000605}{0.3}}=0.011 \mathrm{~m}
\end{gathered}
$$

$\therefore$ Thickness of base plate $=11 \mathrm{~mm}$ 
Although the tower weight load is at the center of the base plate, with the action of wind power on the tower, the load tilt from one side to the other, that's why the bolts were considered to be under eccentric loading. Therefore, if $d_{c}$ is the core diameter or simply the minimum diameter of the bolt and $\sigma_{\mathrm{t}}$ is the tensile stress for the bolt material, then the total tensile load on the heavily loaded bolt is given as [14]:

$$
W_{t}=\frac{\pi}{4} d_{c}^{2} \sigma_{t} \ldots \ldots \ldots \ldots \ldots(X V I I I)
$$

Where: $\sigma_{\mathrm{t}}=52 \mathrm{Mpa}$ (allowable stress for steel)

$w=\frac{\text { Moments on Pivot }}{\text { one }}=\frac{6730.818 \mathrm{Nm}}{1 \mathrm{~m}}=6730.818 \mathrm{~N}$ (i.e load supported by bolts or hinge)

Consider the base plates to be loaded parallel to the axis of bolts by an eccentric load

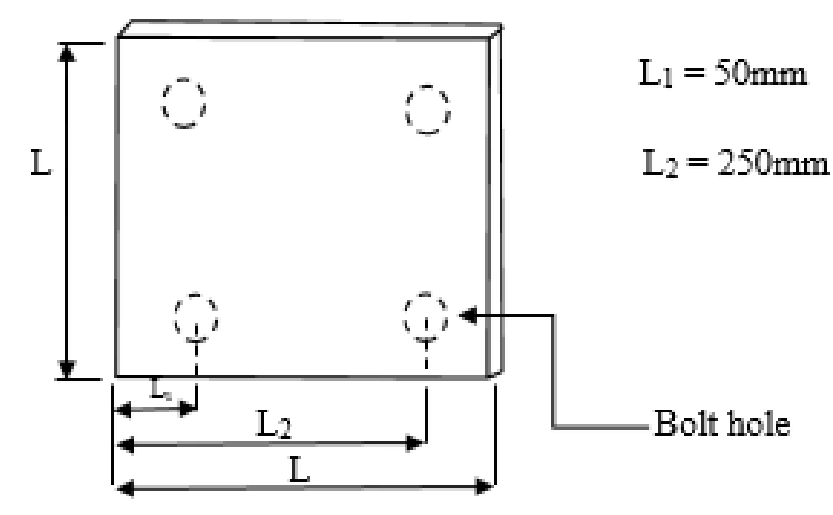

Figure 7. A base plate

The load carried by each bolt $=\frac{W}{n}=\frac{6730.818}{4}=1682.705 \mathrm{~N}$

$\therefore$ Load in each bolt per unit distance from the tilting edge is given by:

$$
w=\frac{W L}{2\left[\left(L_{1}\right)^{2}+\left(L_{2}\right)^{2}\right]}=\frac{6730.818 \times 300}{2\left(50^{2}+250^{2}\right)}=15.533 \mathrm{~N} / \mathrm{mm}
$$

Since the heavily loaded bolt is at distance $\mathrm{L}_{2}$ from the pivot, which is the load on the hinge rod during erecting up and down of tower, therefore the load on the heavily loaded bolt which is equal to load on the hinge rod is given by:

$$
w_{L_{2}}=w L_{2}=15.533 \times 250=3883.164 \mathrm{~N}
$$

Maximum tensile load on the heavily loaded bolt, which is also the maximum tensile load on the hinge rod during erection of tower, is given by:

$\mathrm{W}_{\mathrm{t}}=\mathrm{W}_{\mathrm{tl}}+\mathrm{W}_{\mathrm{L} 2}=1682.705+3883.164=5565.869 \mathrm{~N}$

$$
\therefore \quad d_{c}=\sqrt{\frac{4 W_{t}}{\pi \sigma_{t}}}=\sqrt{\frac{4 \times 5565.869}{\pi \times 52 \times 10^{6}}}=11.7 \mathrm{~mm}
$$

$\therefore \quad$ Hinge rod diameter $=12 \mathrm{~mm}$

While from the table of standard dimensions of screw threads for design of screw thread, bolts and nuts according to IS: 4218

For $\mathrm{d}_{\mathrm{c}}=11.546 \mathrm{~mm}$, corresponding size of bolt is M14

$\therefore \quad$ Bolt size $=M 14$ 


\section{RESULTS}

The table of results below, shows the tower components designed for this study.

Table 2. Components of the tower designed

\begin{tabular}{|l|l|c|}
\hline S/N & \multicolumn{1}{|c|}{ COMPONENT OF THE TOWER } & RESULT \\
\hline 1 & Diameter of upper steel pipe tower material & $51 \mathrm{~mm}$ \\
\hline 2 & Diameter of middle steel pipe tower material & $73 \mathrm{~mm}$ \\
\hline 3 & Diameter of lower steel pipe tower material & $89 \mathrm{~mm}$ \\
\hline 4 & Stiffness of the weak section of the tower & $8633 \mathrm{kN} / \mathrm{m}$ \\
\hline 5 & Natural frequency of the tower & $191 \mathrm{~Hz}$ \\
\hline 6 & Overturning moments on jack in lifting the tower & $6730.818 \mathrm{Nm}$ \\
\hline 7 & Force required to lift the tower at fulcrum & $20,192.5 \mathrm{~N}$ \\
\hline 8 & Calculated size of the jack recommended to lift the tower & $2,575 \mathrm{~kg}$ \\
\hline 9 & Diameter of hinge rod material & $12 \mathrm{~mm}$ \\
\hline 10 & Thickness of base plate material & $11 \mathrm{~mm}$ \\
\hline 11 & Number of bolts required for the tower & $46 \mathrm{~km} / \mathrm{h}$ \\
\hline 12 & Size of bolts required to hold the tower & \\
\hline 13 & Highest peak wind speed measured for the site & \\
\hline & & \\
\hline
\end{tabular}


International Journal of Engineering Research And Advanced Technology, Vol.6 (12), December-2020

4.1 Working drawing

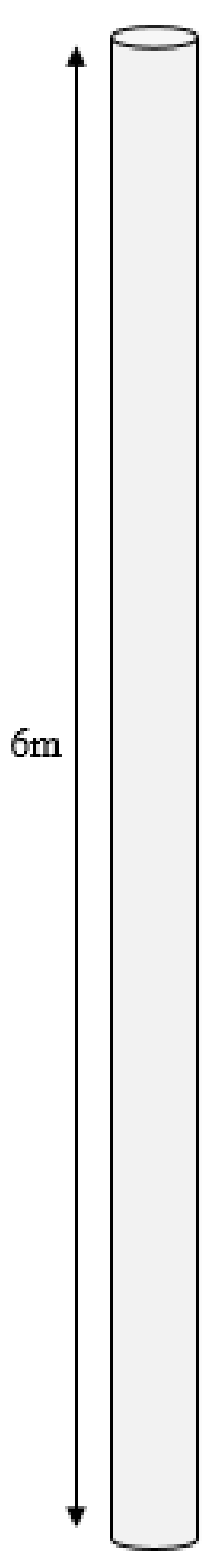

2" Steel Pipe

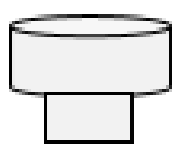

Reducer socket $3^{\prime \prime}-2^{n}$

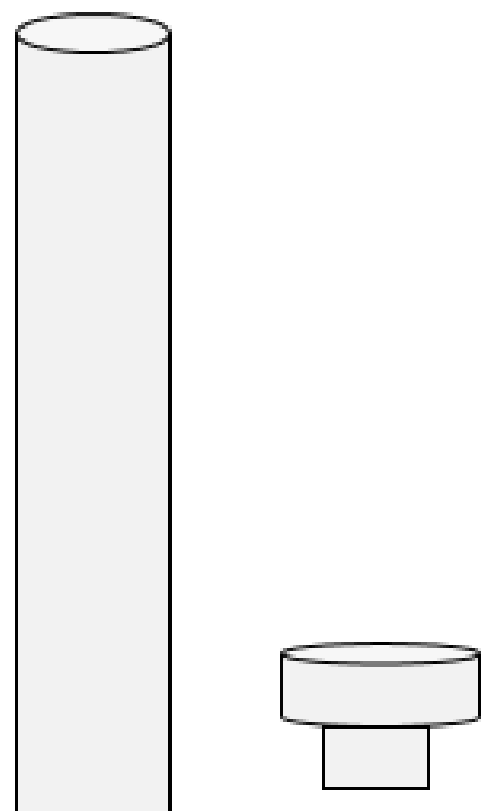

Reducer socket $4 "-3 "$

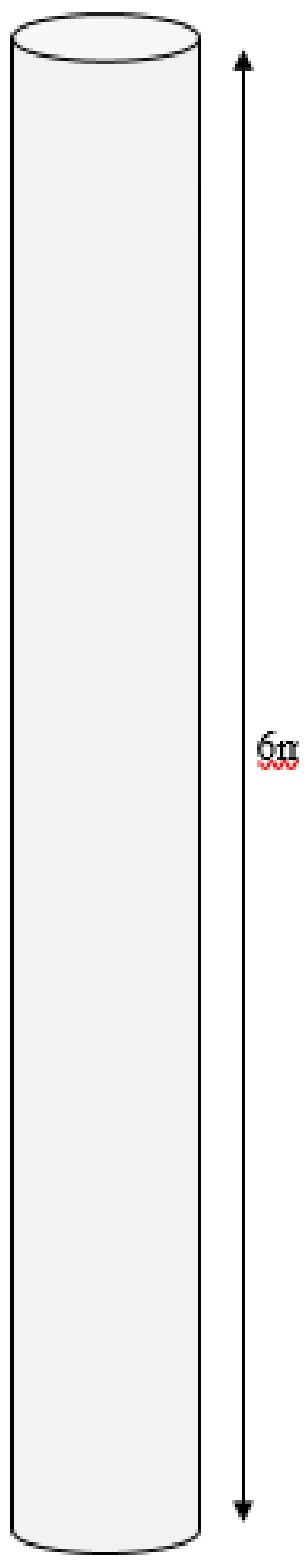

$4^{n}$ Steel Pipe

Figure 8. Tower pipes and reducer joints. 
International Journal of Engineering Research And Advanced Technology, Vol.6 (12), December-2020

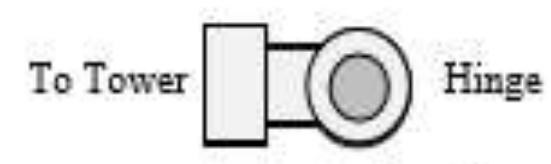

To top of a Jack

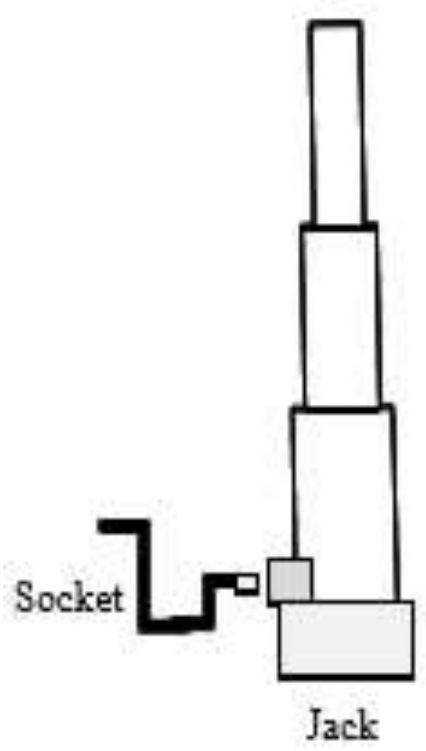

To bottom of a Jack

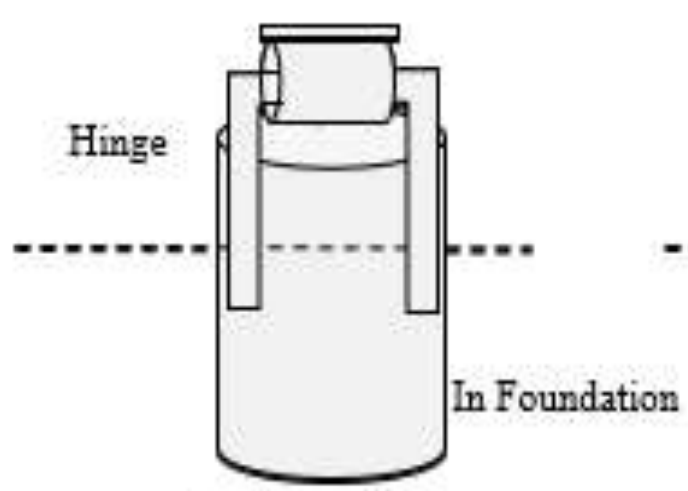

Jack Foundation

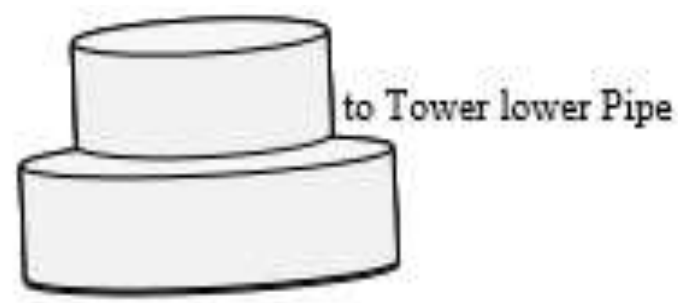

6"- 4" Reducer to one Base Plate

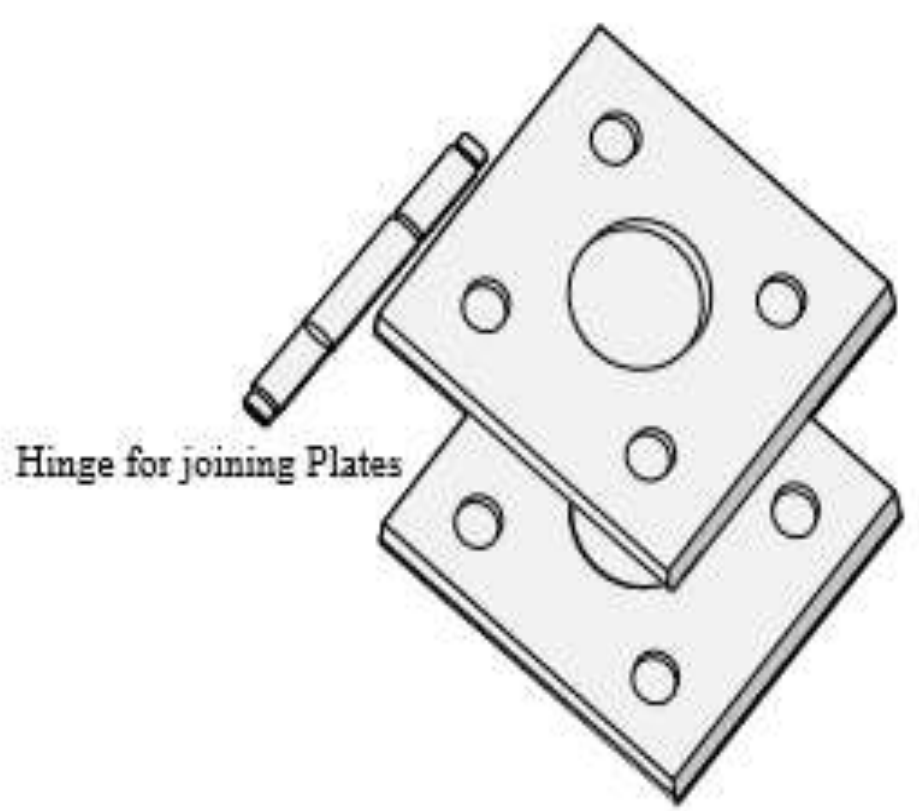

one Base Plate to top of Tower Bage

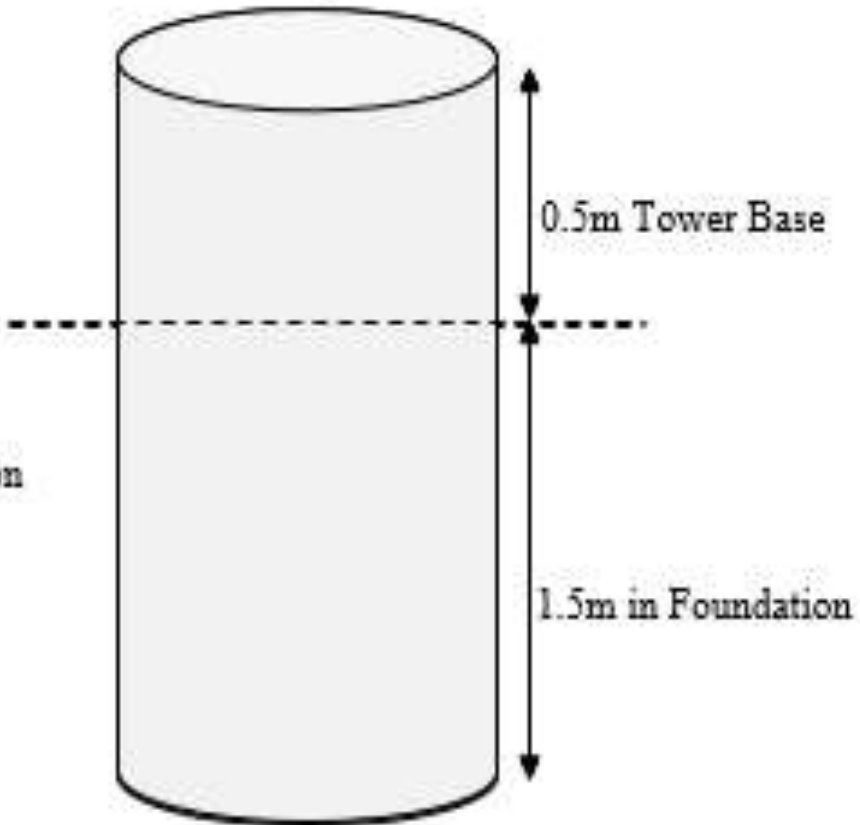

6" Pipe for Tower Base Foundation

Figure 9. Other tower parts. 


\subsection{Assembly drawing}

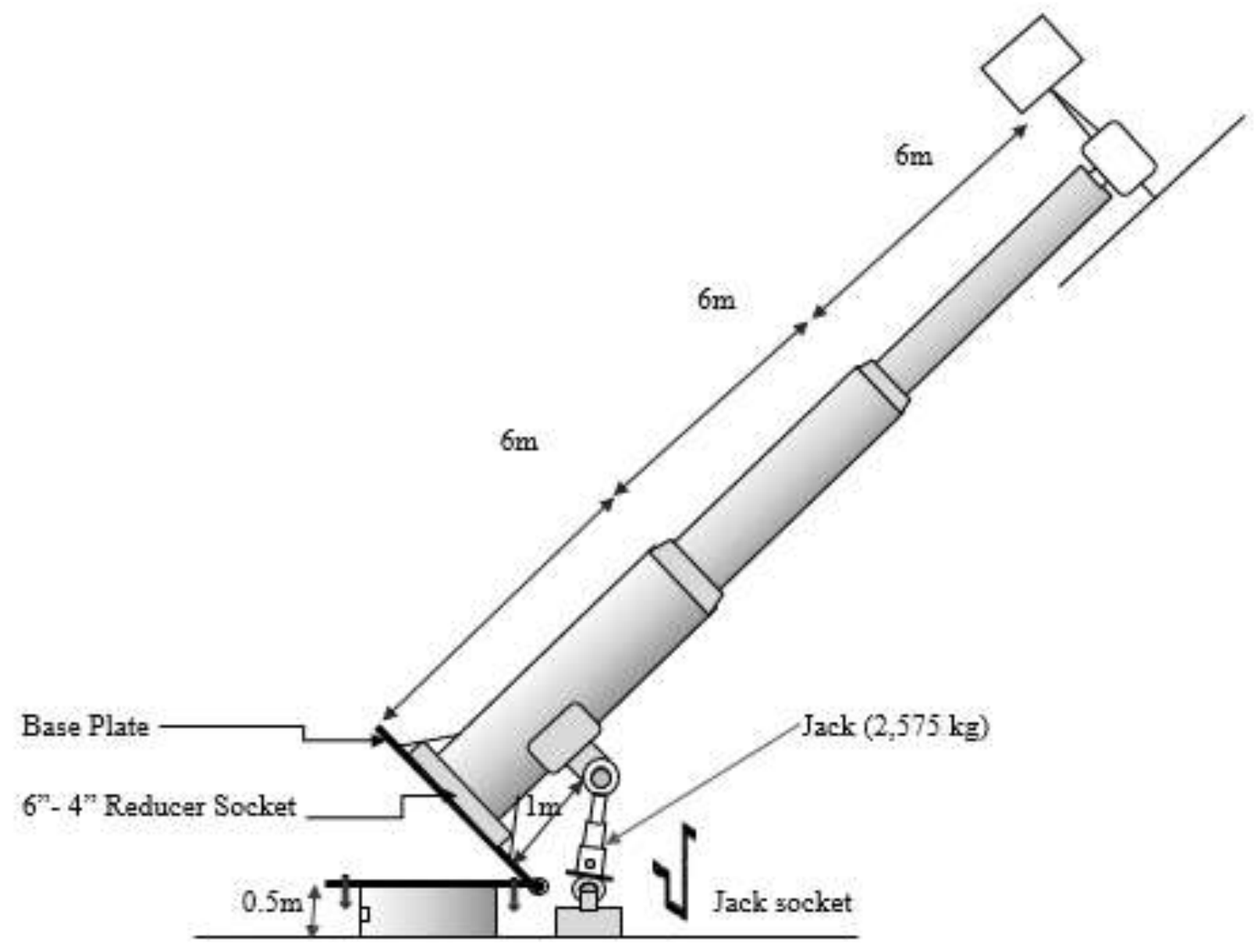

Figure 10. Assembly drawing of the self-erecting tower.

\subsection{Discussion}

From table 2 of the results, it can be seen that the calculated diameter of pipes in designing the tower are increasing toward the base, this is to conform with the standard tubular steel towers, that are formed in conical shapes, and this is to increase the stability of the tower. While the force required to lift the assembly of the tower is calculated to be $20,192.5 \mathrm{~N}$ or $20.2 \mathrm{kN}$, the capacity of the jack required to lift the tower exceeds this value. This is to ensure that the jack does not fail in lifting the tower, which may cause the damage of the tower during erecting-up or in bringing down the tower. Adopting a factor of safety of 3 as for some machine design (ETB, 2016), the size of the jack selected is the one which by utilizing 80 percent of its recommended capacity, can lift the tower up and bring down safely, and is calculated to be $2575 \mathrm{~kg}$, with the fulcrum at $1 \mathrm{~m}$ from the pivot.

The hinge rod where the fulcrum is located is where the tower was supported, and the hinge rod at the pivot is where the tower rotates, each of these rods are $12 \mathrm{~mm}$ in diameter. While the base plates that are located in between the lower reducer socket and the base pipe of the tower were found to be $11 \mathrm{~mm}$ thick. Also, the number of bolts to tighten the tower to the base is 4 , as it is recommended to use 4 bolts for coupling of materials of diameter above $40 \mathrm{~mm}$ up to $100 \mathrm{~mm}$ in design of bolts (Kurmi and Gupta, 2005). And the size of bolts to use, for the calculated value of core diameter which correspond to a table of standard dimensions of screw thread is M14 according to IS: 4218.

Figure 6 shows the designed pipes each with uniform cross-section and of different diameters, also the reducer sockets of the corresponding pipes were to be used in joining the pipes. Other designed parts are shown in Figure 7, which include the hinges, the base plates, the tower base foundation pipe, the jack base foundation pipe and the jack selected.

\section{CONCLUSION}

The tower designed in this research work consists of three steel pipes of different diameters calculated to be $51 \mathrm{~mm}$ which correspond to 2 inches from the standard pipes, $73 \mathrm{~mm}$ which is approximately 3 -inch pipe, and 89 mm which is rounded up to correspond with 4-inch pipe. The pipes were connected using steel reducer sockets, and then the joints welded to obtain a permanent solid tower. The assembly of the tower required a calculated force of $20.2 \mathrm{kN}$ to be lifted, and therefore to satisf $\mathrm{y}$ the 
factor of safety, the size of the jack selected was the one which by utilizing a maximum of 80 percent of its recommended capacity can erect the tower up and bring it down safely. The size of the jack was calculated to be $2575 \mathrm{~kg}$. The self-erecting design was achieved by designing a tower that can be erected-up by changing the angle of inclination of the tower from a certain angle above zero degree to the horizontal to a maximum angle of 90 degrees to the horizontal.

The idea employed in this research work provides a solution to the inconveniencies associated with the mobile cranes access to the installation site, and the turbine machine can easily be brought down for lubrication and repair services without the need of any supporting machine. This research work encourages the use of available renewable energy sources in generating electricity for domestic use, in order to achieve a free polluted and energy sufficient environment.

\section{ACKNOWLEDGMENT}

The authors gratefully acknowledged the effort made to ensure the success of this research work, by the Department of Mechanical Engineering of Kano University of Science and Technology Wudil, 3244 Kano state of Nigeria, Department of Mechanical Engineering of Bayero University, 3011 Kano Nigeria, and Department of Mechanical Engineering of University of Malaya, 50603 Kuala Lumpur, Malaysia.

\section{REFERENCES}

1. Hau, E. and Renouard H. V (2006), The wind resource, Wind Turbines: Fundamentals, Technologies, Application, Economics, P. 451-483.

2. Stavridou, N., Koltsakis E. and Baniotopoulos C (2020), A comparative life-cycle analysis of tall onshore steel windturbine towers. Clean Energy, 4(1): P. 48-57.

3. Koulatsou, K.G., (2020), Resonance Investigation and its Effects on Weight Optimization of Tubular Steel Wind Turbine Towers. Procedia Manufacturing, 44: P. 4-11.

4. Chen, J., Li J. and He X (2020), Design optimization of steel-concrete hybrid wind turbine tower based on improved genetic algorithm. The Structural Design of Tall and Special Buildings, P. e1741.

5. Stavridou, N., Koltsakis E. and Baniotopoulos C (2019), Structural analysis and optimal design of steel lattice wind turbine towers. Proceedings of the Institution of Civil Engineers-Structures and Buildings, 172(8): P. 564-579.

6. Wang, T. and Coton F. N (2001), A high resolution tower shadow model for downwind wind turbines. Journal of Wind Engineering and Industrial Aerodynamics, 89(10): P. 873-892.

7. Murtagh P., Basu B. and Broderick B (2005), Along-wind response of a wind turbine tower with blade coupling subjected to rotationally sampled wind loading. Engineering structures, 27(8): p. 1209-1219.

8. Kim D. M (2009), Structural Vibration Characteristics of a MW-Class Wind Turbine Tower Considering Earthquake Base Excitation. in Proceedings of the Korean Society for Noise and Vibration Engineering Conference, The Korean Society for Noise and Vibration Engineering.

9. Hong H. S (2006), Research for 2MW Wind Turbine Tower Shell Design Optimization. New \& Renewable Energy, 2(4): P. 19-26.

10. Blattner D (2003), A Self-Erecting Method for Wind Turbines. Phase 1: Feasibility and Preliminary Design.

11. Dimopoulos C. and Gantes C (2013), Comparison of stiffening types of the cutout in tubular wind turbine towers. Journal of Constructional Steel Research, 83: P. 62-74.

12. Stavridou, N (2015), Investigation of stiffening scheme effectiveness towards buckling stability enhancement in tubular steel wind turbine towers. Steel and Composite Structures, 19(5): p. 1115-1144.

13. Brockenbrough, R. L. and Merritt F. S (1999), Structural steel designer's handbook. Citeseer.

14. Khurmi, R. and Gupta J (2005), A Textbook of Machine Design. Ram Nagar, New Delhi, India: Enrasia Publishing House (PVT) Ltd.

15. The Engineering Toolbox (ETB) (2016), Factor of Safet, Retrieved from: www.engineeringtoolbox. com/factor-safetyfos-d_1624.html Accessed 16th October, 2016.

16. The Engineering Toolbox (ETB) (2016). Young Modulus of Elasticity of Materials. Retrieved from: www.engineeringtoolbox.com/young-modulus-d_417.html Accessed 15th October, 2016. 